\title{
As cigarreiras revoltosas e o movimento operário: história da primeira greve feminina do Recife e as representações das mulheres operárias na imprensa*
}

Felipe Azevedo e Souza**

\section{Resumo}

A greve das cigarreiras de 1903 foi encetada pela demissão das primeiras quatro mulheres a ingressarem no movimento operário do Recife. Com o objetivo de compreender as motivações que levaram essas trabalhadoras a se organizarem politicamente, este artigo analisa os eventos em torno da greve e as representações sociais que situavam o trabalho de mulheres em fábricas como uma prática moralmente reprovável. O exame das questões propostas evidencia que as cigarreiras se apropriaram das plataformas de ação fornecidas pelo movimento operário para conquistar visibilidade em um processo de estabelecimento de uma identidade de gênero relacionada ao trabalho.

Palavras-chave: Movimento Operário, Greve, Operárias, Identidade de Gênero.

" Recebido em 07 de abril de 2015, aceito em 07 de fevereiro de 2019.

** Doutor em História Social pela Universidade Estadual de Campinas (Unicamp). Bolsista de Pós-Doutorado pela CAPES na Universidade Federal da Bahia (UFBA). felipeazv.souza@gmail.com / https://orcid.org/0000-0002-6232-3273 
cadernos pagu (55), 2019:e195513 As cigarreiras revoltosas e o movimento operário: história da primeira greve feminina do Recife e as representações das mulheres operárias na imprensa

The "Cigarreiras Revoltosas" and The Labor Movement:

A History of The First Strike by Working Women in Recife and Representations of Women Workers in The Press

\begin{abstract}
A 1903 strike of tobacco workers' was triggered by the layoff of the first four women who joined the labor movement in the city of Recife. To understand why these women workers organized politically, the article analyzes events related to the strike and social representations of female work in factories as morally reprehensible. The examination of the questions raised reveals that the tobacco workers appropriated the platforms for action provided by the labor movement to gain visibility in a process of establishing a work-related gender identity.
\end{abstract}

Keywords: Labor Movement, Strike, Women Workers, Gender Identity. 
"É preciso ter ciência", dizia Benedita Rodrigues da Silva sobre o trabalho de fazer charutos. Outra charuteira afirmava "que tinha gente que tinha a mão pesada, fazia charuto apertado $e$ pesado, mas tinha outras que não. Essas coisas todas. Tinha bico batido, tinha bico lançado, bico de ponta, bico de bojo, tinha charuteira de primeira, tinha de segunda". Esses depoimentos são de charuteiras que trabalhavam em uma grande fábrica no Recôncavo baiano em meados da década de 1940, período em que as mulheres eram a principal força de trabalho na produção de cigarros e charutos, em muito por uma divisão do trabalho que atrelava o ofício de enrolar fumo a características atribuídas às mulheres, como a delicadeza e a paciência que eram exigidas para confeccionar centenas de cigarros ou charutos, um por um, dia após dia, sentadas em um banco apoiadas a um pequeno tablado, inalando o cheiro forte do fumo (Silva, 2011). ${ }^{1}$

É muito provável que essa concepção que relacionava o ofício às mulheres já existisse na passagem do século XIX para o $\mathrm{XX}$, no entanto, naquele momento tal associação era tensionada por entrar em contradição em relação às funções socialmente estabelecidas para o sexo feminino que baseavam-se essencialmente em atribuições pautadas por questões familiares $e$ aos afazeres domésticos. Um discurso moral que era usualmente utilizado para vetar o acesso das mulheres ao mercado de trabalho (Weinstein, 1995). ${ }^{2}$

1 A citação de Benedita da Silva encontra-se na página 86, já a segunda, de Dalva Damiana dos Santos, está na página 88. Ambas foram coletadas pela pesquisadora. Sobre as características do ofício serem atribuídas as mulheres, ver especialmente na página 68 os depoimentos de pessoas envolvidas com os proprietários das fábricas. Ainda que as descrições do trabalho sejam para charutos, não para cigarros, e datem 40 anos depois do recorte temporal dos eventos analisados neste artigo, as técnicas de enrolar fumo e o regime de trabalho para os dois contextos eram bastante semelhantes.

2 Ainda que na parte final deste texto essa concepção venha a ser esmiuçada para a realidade do Recife, deixo desde já a indicação do texto de Barbara Weinstein sobre os conflitos em torno da construção de identidades femininas relacionadas ao trabalho assalariado, e principalmente industrial, em São Paulo durante a primeira metade do século XX. No artigo, a historiadora chega a 
A virada do século foi justamente o momento de transição em que esses conceitos morais começaram a ser revistos; vivia-se então uma fase importante na divisão sexual do trabalho no Brasil (Kergoat, 2000). ${ }^{3}$ Nesse período, as mulheres não estavam totalmente estabelecidas no mundo do trabalho fabril, elas enfrentavam ainda certa resistência para ocupar postos em algumas fábricas de cigarro. A do Recôncavo, por exemplo, em 1906 empregava apenas duas charuteiras, diferentemente de 1940, quando elas eram 686. A maior fábrica de Recife, a Lafayette, que produzia especialmente cigarros, em meados de 1890, empregava apenas homens, mas alguns anos depois tinha seus galpões ocupados majoritariamente por mulheres. ${ }^{4}$

Essa fábrica pernambucana será o cenário privilegiado de alguns eventos narrados neste artigo. A contratação de cigarreiras em substituição contínua e gradual à mão de obra masculina trouxe à tona uma série de discussões sobre os papéis que eram estabelecidos para as mulheres em relação ao trabalho nas indústrias. O debate ganhou vigor quando algumas cigarreiras da Lafayette ingressaram no movimento operário, à época pulsante e em plena expansão, fundando a Secção Feminina do Centro Operário e ocupando postos de protagonismo social e de atuação política que conferiram novas imagens e valores em relação às identidades socialmente convencionadas para as mulheres das

afirmar que "com a única exceção das prostitutas, a figura feminina mais estigmatizada ou problematizada no setor trabalhista era a operária industrial".

3 O percurso do conceito de divisão sexual do trabalho é sinteticamente explorado em um texto de Danièle Kergoat. A historicidade do conceito evidencia a forma com que a análise das relações sociais em torno do trabalho ganharam com um paradigma que identificou as bases das construções sociais que organizavam o poder $e$ as hierarquizações de características que imprimiam as diferenças dos indivíduos baseadas em uma identidade de gênero.

4 O mesmo era válido para outros países, nas tradicionais fábricas de Valência na Espanha, as mulheres eram numerosas no século XIX, mas só se tornam hegemônicas perto da metade do século XX. O mesmo para os Estados Unidos. Ver Gallego (2007), Ruiz; Korrol (2006). 
classes trabalhadoras. ${ }^{5}$ Nessa senda agitaram-se greves $e$ discussões nas colunas de jornais, episódios que serão visitados nas próximas páginas.

\section{Mão de obra em transição e greve: narrativas do trabalho no começo do século XX}

Carroceiros, estivadores, operários da estrada de ferro, maquinistas, foguistas, empregados da companhia de esgoto e até os jóqueis do hipódromo, trabalhadores de várias categorias encamparam uma ampla onda de greves no Recife entre 1890 e início de $1896 .{ }^{6}$ No auge desse momento de conflito entre a classe trabalhadora $e$ a patronal, os operários de uma das maiores fábricas de cigarros da cidade, que empregava centenas de trabalhadores, viviam um momento de comunhão com seu patrão. Em certa tarde de um domingo de outubro de 1895, mais de 100 operários da fábrica Lafayette homenagearam seu empregador, o Sr. Manoel Pontes de Souza Moreira, com discursos, brindes e até mesmo com a entrega de um retrato a óleo do industrial figurado em "elegante moldura". Toda essa distinção foi feita em agradecimento aos "relevantes serviços prestados" por ele aos trabalhadores da fábrica (Manifestação..., 8 out. 1895).

5 O centro operário, como à época era chamado $\mathrm{O}$ Centro Protetor dos Operários, foi uma associação de resistência fundada principalmente por trabalhadores das estradas de ferro de Pernambuco em 1900, mas que em pouco tempo se tornou a principal entidade de articulação do movimento operário em Pernambuco e nos estados vizinhos. Ao longo da primeira década do século XX, dezenas de associações de ofício passaram a se coligar ao centro, que chegou a ter mais de seis mil trabalhadores registrados em suas fileiras. Sobre o centro, ver: Souza (2018), em especial o capítulo VI.

6 Em levantamento sobre as greves registradas na imprensa pernambucana, computei que ao longo da década de 1880 foram deflagradas apenas 4 greves. Esses dados aumentam vertiginosamente na década seguinte: entre 1890 e 1896, foram ao menos 36 movimentos grevistas. Para detalhes sobre esses índices e as razões desse incremento, ver: Souza (2018). 
cadernos pagu (55), 2019:e195513 As cigarreiras revoltosas e o movimento operário: história da primeira greve feminina do Recife e as representações das mulheres operárias na imprensa

Além do aumento salarial, causa comum nas outras greves que pipocavam na cidade, os cigarreiros declaravam-se agradecidos na imprensa por uma questão muito específica: a eliminação das mulheres das oficinas da fábrica. Em nota publicada meses antes na imprensa, "os operários da fábrica Lafayette" agradeciam aos patrões pelo que chamavam de um "ato de equidade e reconhecida justiça", pois o trabalho feminino implicava "desleal competição" com o dos homens e só se justificava por "efêmeras vantagens" (Agradecimento, 13 fev. 1895).

$\mathrm{Na}$ escala social do trabalho as operárias estavam alguns degraus abaixo dos operários. Diante dos homens pobres, a maior parte das mulheres da mesma classe via-se em uma realidade de mercado de trabalho mais restrito, níveis de qualificação mais baixos, sem participação em sociedades ou associações de classe e sem acesso a direitos políticos, apenas para citar alguns dos fatores que pesavam objetivamente no contexto. Em suma, estavam inseridas em uma estrutura social mais excludente na generalidade dos âmbitos de classificação e tinham chances de ascensão profissional, e mesmo de estabilidade, diretamente obstruídas por essas características que circunscreviam sua identidade de gênero diante do mercado de trabalho (Scott, 1989). ${ }^{7}$

Nesse sentido, mulheres cujo próprio sustento e o de seus familiares dependia apenas de sua força de trabalho não tinham muitas possibilidades além de se submeter a salários mais baixos que os dos homens. Era a essa questão que os cigarreiros se referiam quando falavam em "desleal competição" com o dos homens e em "efêmeras vantagens" para os proprietários.

Em tal contexto a contratação ou a demissão de operárias servia a um duplo influxo de interesse para o proprietário da

7 Identidade de gênero aqui compreendida no sentido em que os papéis sexuais eram assimilados como categorias sociais pelas instituições e vivenciados cotidianamente na organização $e$ na manutenção das diferenciações $e$ hierarquias entre homens e mulheres como um eixo criador de desigualdades em diversas escalas de relações, como, por exemplo, o acesso ao trabalho assalariado. Essa dimensão estrutural é basilar para compreender o desenvolvimento das relações de gênero no universo do trabalho no século XIX. 
fábrica de cigarros. Por um lado podia lhe ser útil para o aumento dos lucros da empresa a partir da exploração de uma mão de obra mais barata. E por outro lado lhe era conveniente para conter os ânimos dos trabalhadores mais combativos que exigiam direitos, já que esses se viam ameaçados pela possibilidade de serem substituídos pelas mulheres, afinal de contas sobre elas não havia registros que participassem de organizações operárias, nem constava histórico de greves ou sublevações. Essa prática que fica subentendida por relatos de membros do movimento operário $e$ por demissões sob o pretexto de "mau comportamento", só mais tardiamente é colocada em claras letras por uma comissão de cigarreiros da Lafayette, que em 1906 assinava uma nota no jornal negando que "premeditavam uma greve":

[...] nós não cogitamos tal greve, estamos satisfeitos desde que nossos patrões sustentem trabalho com fartura a fim de tirarmos um salário regular para manutenção de nossas famílias, e sem capricho nem perseguições de parte a parte mesmo porque temos a certeza que nossos patróes aborrecidos com as últimas greves, estão dispostos no caso de greve a suprimir a secção de homens, o que nos prejudicaria, e como estamos dispostos a manter a melhor harmonia entre patrões $e$ operários fazemos a presente declaração (Protesto..., 11 mar. 1906).

Essa instrumentalização da contratação de mulheres para o controle político dos operários ganha nitidez com o acompanhamento das disputas entre trabalhadores $e$ o proprietário da fábrica Lafayette. Quando na comemoração de 1895 os operários pediam que seus patrões permanecessem "inabaláveis no propósito e resolução que tomaram" de extinguir a seção feminina da fábrica, talvez soubessem que estavam à mercê desse expediente.

No correr dos anos seguintes, os operários que haviam afirmado uma "eterna gratidão" ao seu patrão Manoel Pontes, não pareciam mais tão satisfeitos com as condições de trabalho como naquela festiva tarde de domingo. No começo de 1899, os 
cigarreiros entraram em greve porque tiveram seus salários reduzidos (Operários..., 3 jan. 1899). Pouco tempo depois, em 1901, houve uma leva de demissões de cigarreiros porque mantinham "comportamento irregular" (Fábrica..., 24 jan. 1901). Em 1902 houve novamente uma ameaça de greve na Lafayette que se desfez após uma mesa de negociação com a intervenção de membros da Associação dos Merceeiros que, segundo os cigarreiros, conseguira "abrandar o coração de ferro" dos patrões (Agradecimento, 19 out. 1902). Enfim, ao longo desses anos, os registros na imprensa sobre as relações de trabalho na fábrica são difusos e raros. Para nenhum desses casos há um acompanhamento programático da imprensa, apenas notas eventuais publicadas pelos próprios operários. No entanto, em todas essas manifestações se revelam indícios de um estremecimento na relação entre os trabalhadores e o patrão.

Talvez como causa, talvez como consequência, mas provavelmente não por mera coincidência, ao mesmo tempo começaram a aparecer discretas notas nos jornais que denotavam a volta de operárias femininas à fábrica Lafayette. Em 1901 um vizinho da fábrica de cigarros reclamava do alarido e da algazarra que faziam as cigarreiras ao deixarem o armazém (Seç̧ão..., 11 mai. 1901). Naquele mesmo ano as cigarreiras aparecem numa lista de doadoras de alguns vinténs para ajudar a quermesse em benefício da liga contra a tuberculose (A Província, 25 ago. 1901). E, em 1902, a fábrica anunciava que precisava "de uma senhora de conduta afiançada para fazer parte da gerência e que escreva desembaraçado [sic.]" (A Província, 15 jan. 1902).

Provavelmente elas se tornaram maioria antes de 1903, pois naquele ano na sede de produção trabalhavam 260 cigarreiras e 180 cigarreiros (Greve..., 3 set. 1903). Algumas das que trabalhavam ali foram as primeiras mulheres a ingressarem no movimento operário em Pernambuco. Ainda no começo de 1903, seis delas fundaram a Secção Feminina do Centro Operário, metade delas ocupava postos de liderança na fábrica, eram diretoras $e$ subdiretoras. 
Diante da indisposição do proprietário da fábrica em relação ao movimento operário, a decisão de integrar o centro operário era arriscada, talvez por isso ela tenha sido tomada conjuntamente por algumas das funcionárias mais importantes da fábrica. Estratégia que não surtiu efeito, pois pouco tempo depois quatro das seis diretoras do centro operário, que trabalhavam na Lafayette, foram demitidas. O proprietário Manoel Pontes, no entanto, não apenas dispensou as cigarreiras, como fixou um cartaz na parede da oficina feminina com o nome das funcionárias dispensadas. Era uma mensagem evidente para todas as outras sobre a conduta da diretoria em relação àquelas que cogitavam qualquer envolvimento com o movimento operário (Greve..., 3 set. 1903; Cigarreiras..., 3 set. 1903).

As quatro operárias demitidas só souberam que estavam desempregadas ao chegarem no trabalho no início do expediente, às seis da manhã de uma quarta-feira. Duas delas, Edwiges das Chagas, tesoureira da Secção Feminina do Centro Operário, e Antonia Santiago, subdiretora da mesma sociedade, encontraramse na fábrica com o proprietário, o Sr. Pontes Moreira, que segundo os relatos da imprensa exigiu a retirada imediata de ambas da empresa quando elas lhe foram pedir esclarecimentos. $\mathrm{Na}$ ocasião, Pontes usou de "palavras injuriosas" com as operárias, o que gerou revolta nas duas cigarreiras. Nesse momento a situação começou a sair do controle do proprietário da fábrica. Edwiges então se dirigiu a suas companheiras e pediu para que todas abandonassem o trabalho, ao mesmo tempo que Antonia formulava censuras em relação ao procedimento do patrão (Greve..., 3 set. 1903; Cigarreiras..., 3 set. 1903).

Exaltado porque as operárias não se dobraram diante de suas ordens e ofensas, Pontes partiu para a força física, puxando Antonia pelo braço e forçando-a a descer a escada. Conforme relatos de testemunhas, publicados no jornal $A$ Província, "o Sr. Pontes Moreira não se limitou aos puxões e ela [Antonia] foi espancada pelo mesmo senhor". O Diário de Pernambuco noticiou que Pontes "esbordoou" a operária (Greve..., 3 set. 1903; Cigarreiras..., 3 set. 1903). 
As mais de 250 cigarreiras que presenciaram a altercação reagiram de maneira enérgica. Ainda segundo $A$ Província, aos gritos de "Viva o Centro Operário! Viva Adelaide dos Santos!", as operárias começaram a deixar a fábrica coletivamente e em extrema agitação, "derramando-se pelo pavimento tabuleiros $e$ depósitos de fumo, cigarros, mortalhas e rótulos" e quebrando as vidraças do vasto salão onde até meia hora antes começariam mais um dia de trabalho ordeiro. Em meio à gritaria $e$ ao quebraquebra "algumas das operárias foram acometidas de ataques de nervos e outras, espavoridas, saltaram das janelas para o telhado do prédio contíguo".

Outro periódico, o Jornal do Recife, publicou uma lacônica matéria sobre o levante das cigarreiras, chamando inclusive de "pequeno tumulto" o que havia acontecido. No entanto, não deixou de franquear uma longa coluna na primeira página para que o proprietário da fábrica conseguisse, nas suas palavras, tornar "restabelecida a veracidade" dos fatos ocorridos e que vinham sendo "deturpados com malévolos intuitos" pelas cigarreiras. Moreira afirmava que resolveu dispensar "quatro operárias cigarreiras, reconhecidas aliciadoras da indisciplina", quando uma das que havia sido demitida fomentou grande balbúrdia, inclusive atentando contra a segurança dele, ao ser "invectivado pelas mais exaltadas [...] que pretenderam cerca-lo ameaçadoras", em reação disse que "agarrou por um braço a amotinadora e obrigou-a a descampar". Ainda que na sua própria versão, a violência que utilizou não tenha sido a motivadora do levante das cigarreiras, mas, na verdade uma forma de se defender delas, ele não deixou de vaticinar que estava "disposto a agir energicamente para coibir os abusos das cigarreiras", que foram divididas por ele entre conspiradoras e iludidas (Levante..., 3 set. 1903). ${ }^{9}$

8 Adelaide dos Santos era cigarreira e diretora da secção feminina do centro, gerente da seção feminina da fábrica Lafayette havia três anos e também fora demitida.

${ }^{9} \mathrm{~A}$ mesma carta do Sr. Moreira também foi publicada no jornal $A$ Província. 
O centro operário também publicou uma nota na primeira página do jornal $A$ Província, reiterando, no entanto, a figura do proprietário da fábrica Lafayette como um espancador de mulheres que havia jogado pelas escadas uma operária e utilizado de um vocabulário "ofensivo ao pudor das mulheres honestas" $(\mathrm{O}$ que diz..., 3 set. 1903). Deve ser levado em conta que na nota de repúdio escrita pelo dirigente do centro havia implicitamente a defesa da própria associação operária, visto que as demissões das cigarreiras atentavam antes de tudo contra a entidade.

Cabe notar que a imprensa mandou jornalistas para a fábrica, publicou as versões do centro operário e do Sr. Manoel Pontes, mas em nenhum momento as letras dos jornais conformaram as palavras das cigarreiras violentadas e demitidas. Ainda que horas depois de terem sido agredidas elas tenham formado uma comissão $e$ visitado as redações de alguns periódicos da cidade, estes se limitaram a registrar a visita, não se preocuparam em lhes dedicar aspas para suas frases ou publicar notas com seus nomes subscritos. A versão delas simplesmente inexistiu.

No dia seguinte ao conflito da fábrica Lafayette, a seção feminina manteve-se fechada. $\mathrm{Na}$ masculina compareceram apenas 40 operários que trabalharam sob os olhos da força policial, que inclusive havia passado a noite em vigilia resguardando as dependências da fábrica. A maior parte dos operários e operárias da Lafayette estava no Largo do Carmo, onde o centro operário havia organizado um meeting que prestouse a anunciar uma resolução pela greve de todos os trabalhadores $e$ trabalhadoras das fábricas de cigarro do Recife. As reivindicações do movimento eram três: readmissão das operárias demitidas, aumento salarial e redução de uma taxa de limpeza que a fábrica obrigava cigarreiros e cigarreiras a pagar - vale ressaltar que o valor que as operárias pagavam era quase três vezes superior ao pago pelos homens (Greve..., 10 set. 1903).

Não consta que entre os discursos do meeting tenha existido espaço para as mulheres, no entanto, no dia seguinte três delas se fizeram ouvir, quando integraram uma comissão com mais três 
cigarreiros que percorreu as fábricas da cidade em busca de adesão. Na fábrica Caxias, a segunda maior da cidade, as mulheres falaram à suas companheiras e conseguiram interromper o expediente. Os jornais publicaram que 330 operárias da fábrica deixaram o serviço, mas nem todas afirmaram solidariedade ao movimento (Greve..., 5 set. 1903). Ao abandonar o serviço, um grupo de 47 cigarreiras dirigiu-se ao escritório central da empresa para justificar-se com o patrão, alegavam que tinham deixado o trabalho receando sofrerem desagravos das grevistas. De acordo com a mesma matéria, a comissão de trabalhadoras da Caxias que fora se encontrar com o patrão foi coagida pelas mulheres do centro operário que, entre outras ameaças, exclamavam: "ou aderem ou vão se arrepender" (Greve, 5 set. 1903).

As gazetas pintavam uma atmosfera de tensão em torno das fábricas de cigarro, com tropas da cavalaria percorrendo as redondezas e forças da polícia fixas nas portas das indústrias. Por outro lado, os grevistas também fizeram piquetes na Lafayette $e$ chegaram a entrar em conflito com um cigarreiro que havia furado a greve. Por mais de uma semana a produção de cigarros na cidade foi quase que completamente interrompida (Cigarreiras..., 5 set. 1903). ${ }^{10}$

Os líderes do centro operário conseguiram a intervenção do governador para negociar o final da greve e, em reunião fechada com o diretor da Lafayette, ele debateu a possibilidade de atender as reivindicações das grevistas. Das três, apenas uma foi alcançada com sucesso, a de abolir o desconto semanal para limpeza da área de trabalho. $\mathrm{O}$ aumento salarial não foi conquistado, nem a

\footnotetext{
${ }^{10}$ No dia seguinte a greve, o Diário de Pernambuco noticiou que as operárias da fábrica Caxias "que nada tinham de comum com o Centro Operário [...] haviam abandonado a fábrica por intimidação dos operários da Lafayette" e que os cigarreiros da fábrica Merceeiros "aderiram à greve coagidos pelos companheiros exaltados". Independente da procedência da fonte, em todos os dias posteriores enquanto vigorou a greve, as notícias eram que algumas das secções dessas fábricas funcionavam com grande desfalque, enquanto outras não tiveram expediente.
} 
readmissão das cigarreiras demitidas, que, no entanto, acabaram sendo contratadas por outras fábricas de cigarro ao fim da greve.

As conquistas das operárias foram, no entanto, muito além da abolição da taxa de higiene. A própria greve com a mobilização de algumas centenas de operárias, enquanto um fato marcante, foi uma vitória oriunda de um protagonismo social que essas mulheres nunca haviam tido. A desastrosa tentativa do proprietário da fábrica Lafayette de enfraquecer a Secção Feminina do Centro Operário gerou consequências completamente opostas. A greve foi uma plataforma para que as diretoras da seção saíssem às ruas e fábricas a palestrar diretamente com outras trabalhadoras dando visibilidade ao centro e evidenciando a possibilidade de uma postura contrária à ideia de passividade que era socialmente atribuída às operárias pobres.

Depois da greve de 1903 a recorrência com que o tema da autonomia das mulheres e da mão de obra feminina começou a aparecer nos discursos dos líderes operários dá a ver não só a percepção que essas lideranças passaram a ter do potencial de organização e agitação das mulheres, como também da influência crescente da seção feminina junto aos diretores do centro operário (Jornal do Recife, 17 mai. 1905). ${ }^{11}$ Quando em um artigo de jornal em 1903 um secretário do centro defendia que os trabalhadores eram uma só família, afirmando que "entre nós não há distinção de sexo", buscava mostrar que o movimento operário era responsável por uma das poucas possibilidades de discurso institucional na sociedade recifense que acomodava o impulso incontido pela emancipação das mulheres (Greve..., 6 set. 1903; Centro..., 5 jun. 1904).

Pode-se aventar que a seção feminina como um espaço diferenciado no centro fosse um influxo contraditório em relação a

\footnotetext{
${ }^{11}$ Pelo menos uma reunião do centro operário foi inteiramente dedicada ao tema, quando se pronunciaram os discursos "vantagens da associação feminista", por parte do diretor do centro, José Ezequiel, e "o ideal socialista e a mulher", palestrado por Jacques Guimarães.
} 
uma igualdade institucional. No entanto, sua existência era estratégica para dar evidência às expressões das mulheres em uma sociedade onde seu protagonismo e visibilidade eram recorrentemente sufocados. Depois da greve de 1903 as notas na imprensa destacavam em caixa alta os informes da seção feminina e, em solenidades sociais, a presença de operárias que representavam essa seção eram ordinariamente noticiadas, com eventuais alusões a discursos feitos por elas (A Festa..., 27 ago. 1904; Monte..., 15 nov. 1905). Com direção e administração próprias conduzidas por mulheres, a organização notabilizava-se por ser um espaço de criação de uma identidade de gênero para mulheres das classes mais pobres.

Ainda que não tenham ficado registrados os conteúdos dos discursos das mulheres, eventos como a comemoração do primeiro de maio de 1904, resguardam a força simbólica do patamar de autorrepresentação que elas em pouco tempo souberam conquistar. Naquele dia, o teatro mais importante de Pernambuco, o Santa Isabel, recebeu a celebração da data magna dos trabalhadores. A imponente estrutura neoclássica foi adornada para a ocasião pelo Centro Operário e em um palco onde se destacava um grande retrato a óleo de Karl Marx discursaram as principais lideranças do movimento, com destaque para Edwiges Chagas, cigarreira que esteve no centro dos embates da fábrica Lafayette, e Amelia Pinto Damasio, oradora da Secção Feminina ( $1^{\circ}$ de Maio..., 3 mai. 1904).

\section{Fábricas que desvirtuavam mulheres}

Provavelmente não foi por mero acaso que, em um artigo escrito menos de uma semana depois daquela celebração de Primeiro de Maio, três operários cigarreiros protestaram contra "a invasão do feminismo nas oficinas". A partir de argumentos que apelavam para uma suposta proteção das mulheres, o artigo solicitava à inspetoria de higiene que o trabalho feminino nas fábricas de cigarro fosse vetado, baseando-se "nos princípios da razão". Na visão dos cigarreiros, três eram os principais 
inconvenientes do emprego da mão de obra das mulheres: a primeira questão era "física", pois diziam que "o veneno da nicotina e a posição que usam no ato de trabalhar, debilita a mulher e sua delicada constituição física"; o segundo ponto que os desagradava em relação ao trabalho feminino era um tanto insuspeito e pouco sutil, os contrariava o fato de que o trabalho delas implicava no desemprego dos homens. Referia-se ao argumento já evocado outras vezes pelos operários sobre a "concorrência desleal" com as mulheres que, vale sempre lembrar, recebiam menos. Antes da análise do terceiro aspecto é interessante observamos a resposta do inspetor de higiene, Constâncio Pontual, à representação dos operários, que se baseava principalmente nesses dois primeiros argumentos (Serviço..., 10 mai. 1904). ${ }^{12}$

Escrito em dois parágrafos, o parecer do inspetor resume bem uma visão oposta aos dos operários. A sua transcrição integral logo abaixo evidencia que na época havia um conflito de opiniões relativamente maturado no campo discursivo e que podia ocupar as cabeças de alguns agentes do Estado, como foi nesse caso. $\mathrm{O}$ inspetor justificou o indeferimento da representação dos operários da seguinte maneira:

Sob o ponto de vista da higiene a manufatura de charutos $e$ cigarros é igualmente nociva ao homem e a mulher. Ao trabalho tem o homem tanto direito quanto a mulher: pelo trabalho provê o indivíduo (homem ou mulher) a sua subsistência, condição que o livra da miséria, causa mais comum da prostituição. Em todos os países mais civilizados

\footnotetext{
12 Ainda que publicado no dia 10, a representação vinha datada do dia 6 de maio daquele ano. Dias depois o Centro Operário divulgou uma nota rechaçando a ideia de impedimento do trabalho das mulheres, afirmando quanto ao conteúdo da matéria baseada em preceito científicos que: "quem conhece o que é socialismo, quem sabe que em nosso seio tem ingresso a mulher, por cuja emancipação temos o direito de trabalhar, quem sabe enfim qual é o papel que está reservado à mulher na sociedade futura, não pode absolutamente acreditar em tão monstruosa exploração da boa fé das inexperientes operárias" (Centro..., 5 jun. 1904).
} 
cadernos pagu (55), 2019:e195513 As cigarreiras revoltosas e o movimento operário: história da primeira greve feminina do Recife e as representações das mulheres operárias na imprensa

a mulher concorre com o homem ao trabalho $e$ a sua aptidão tem alargado cada vez mais a sua esfera de atividade.

Não cabe a inspetoria de higiene impedir que as mulheres trabalhem com o fim de facilitar aquisição de trabalho ao homem e sim visitar as fábricas e modificar tanto quanto for possível as condições nocivas à saúde de todos os operários (Serviço..., 10 mai. 1904). ${ }^{13}$

Voltando à representação dos operários que listava os "perniciosos efeitos" da "invasão do feminismo nas oficinas", observemos o terceiro aspecto, que nas palavras dos cigarreiros, dizia respeito a questão "moral".

[...] a convivência nas oficinas, por espaço de 8 horas ou
mais, de [mulheres] honestas com outras que não o são,
corrompe-se fatalmente as primeiras, deixando no
esquecimento as boas lições do lar doméstico e, pelo
abandono do mesmo nas horas de trabalho, perde a
mulher o amor à casa e aos bons hábitos ali adquiridos,
reinando uma completa balbúrdia na educação de irmãos
ou filhos (Serviço..., 10 mai. 1904).

A ideia de que a convivência de chão de fábrica corrompia as mulheres honestas, as desvirtuava de seu papel doméstico e mesmo lhes tirava a pureza, era amplamente compartilhada

\footnotetext{
${ }^{13}$ Os mesmos três aspectos estão presentes em um artigo publicado anos depois, em 1910, no jornal Echo do Povo. Nele o redator protesta pelo crescido número de mulheres em relação aos homens nas fábricas de cigarro por causa da "paga feita as mulheres" ser "muito inferior a paga feita aos homens". Além do que o trabalho resultava, segundo ele, no "definhamento e moléstia nas pobres mulheres", de estrutura física mais frágil. Por fim, tal qual a representação dos operários de 1904, afirma que as fábricas são "verdadeiros ladrões de honra" que atiram as operárias na prostituição. Nascimento; Luz, (2012). Operários alagoanos à época, compartilhavam dos argumentos salariais e morais em relação as cigarreiras. Ver: Maciel (2004). Margareth Rago, em trabalho clássico, também escreveu sobre como aquela geração de operários das primeiras décadas do século XX em São Paulo percebia a fábrica como "lugar de degeneração moral, como antro da perdição e da prostituição" Rago (1997).
} 
naquela época. Esse aspecto é objetivamente evidenciado em um pequeno conto ficcional publicado na primeira página do Jornal do Recife em abril de 1900 (A cigarreira..., 29 abr. 1900).

A trama era contada por um narrador onisciente que morava nas proximidades de uma fábrica de cigarros, "cujo pessoal escolhido era quase todo do sexo da tentação e dos nossos pecados". ${ }^{14} \mathrm{Na}$ história, essa percepção que compreendia as operárias como mulheres que eram alvo de impulsos sexuais parecia ser um fenômeno socialmente tolerado. Segundo o narrador, ao passarem na rua elas arrastavam consigo uma "enorme corrente de galanteios chistosos e acanalhados, que eram momento a momento, atirados pelos caixeiros divertidos das primeiras lojas que abriam" e dos "transeuntes mais engraçados e audazes". As investidas a que eram expostas, deve-se ressaltar, eram atiradas no raiar do dia, enquanto caminhavam para o trabalho e mesmo contra o gosto de algumas delas. Como a personagem central do conto, que respondia com um "gracioso muchôcho" ou com palavras de azedume que não eram levadas a sério, pois "todos riam-se de sua linguagem incorreta".

Por essa cigarreira em especial, chamada Rosa, apaixonouse completamente o narrador, não economizando em adjetivos românticos por vários parágrafos para deixar o leitor bem certo desse fato. Até o momento que a história tem sua reviravolta, Rosa passou semanas sem aparecer no trabalho e quando torna está abatida, sua mãe havia morrido. ${ }^{15}$ Rosa que ingressara na

\footnotetext{
${ }^{14} \mathrm{O}$ conto foi escrito por Targino Filho, jovem acadêmico de direito, que como tantos outros aspirantes a bacharel eventualmente se aventurava em escrever contos e poemas em folhas literárias de pouca tiragem. À época contribuía em uma folha do tipo chamado $O$ Derby, onde é provável que tenha tido contato com as mulheres cigarreiras, pois o pequeno jornal era impresso na Fábrica Lafayette, que além da produção de cigarros e charutos possuía uma litografia própria onde confeccionava as caixas e embalagens para seus produtos, mas que também fazia serviços de impressão para terceiros (Nascimento, 1972:451).

${ }^{15}$ Deve-se notar que o narrador, provavelmente para ressaltar o peso do luto de Rosa, pontua que a mãe era "um modelo" de mãe, "dedicada", "cuidadosa", "honesta", "respeitosa", entre outros adjetivos.
} 
fábrica fazia pouco tempo ainda não havia se desvirtuado. No entanto, após perder a referência de família que tinha e passar meses trabalhando em um lugar de poucos "escrúpulos" foi gradativamente passando por mudanças de personalidade.
A sua vida, outrora irrepreensível, tornou-se desregrada $e$ reprovável.
O meio a tinha corrompido extraordinariamente.
Ela não era mais a flor das cigarreiras.
E dela já dizia tanta coisa, tanta coisa...
- Se ela possuísse uma filha, afirmava, não botá-la-ia em
Fábricas...
- Pobre menina! (A cigarreira..., 29 abr. 1900).

Duas concepções estavam em jogo, a que entendia que o trabalho fabril corrompia as mulheres $e$ as afastava do fundamental papel que tinham na sociedade, ligado basicamente aos deveres domésticos e familiares, e a outra que o inspetor de higiene defendia, em torno de seu direito ao trabalho (Agradecimento, 18 mai. 1904). Ou seja, estamos diante de duas posições contrárias sobre o direito ao trabalho fabril, no entanto, contraditoriamente também estamos diante de um panorama em que os opostos se encontram quando buscam justificar-se.

Se na representação dos operários e no conto $A$ Cigarreira, o ambiente da manufatura afastava as mulheres dos valores familiares, lhes deteriorando moralmente, na visão do inspetor, o trabalho era necessário, pois as livrava da miséria, que afirmava ser a "causa mais comum da prostituição". Ora, a prostituição nessa época era uma categoria que se projetava diretamente em oposição à família. As duas eram inconciliáveis em termos discursivos. Dizia-se que onde havia a forte presença de uma, não florescia a outra. Uma oposição cuja metáfora espacial traduzia-se inclusive nas dimensões materiais da geografia e do trânsito das cidades. A historiografia mostra que havia um ferrenho conflito moral em torno das áreas de prostituição; nas zonas de meretrício do Rio de Janeiro dizia-se "que nenhuma família grave, a não ser muito pobre, se sujeita a morar", ou que em certos pontos "não 
poder passar nenhuma família" (Silva, 2012). Até os teatros ambientavam essa tensão. Segundo o romancista Artur Azevedo, as casas de espetáculo estavam sendo cada dia mais frequentadas por "rameiras", tornando-se um ambiente impróprio para famílias decentes (Silva, 2014).

Provavelmente era entre esses dois polos de representação que delimitava-se socialmente a figura feminina, principalmente as mulheres mais pobres. Uma identidade que trazia consigo um movimento praticamente inevitável em relação à família, ou seja, a família era o referente exterior fundamental que definia as mulheres ou que engendrava uma concepção amplamente aceita em torno do que era ser mulher, servindo inclusive como parâmetro básico que intermediava as relações de gênero. Ainda que as práticas sociais multiplicassem experiências capazes de transcender a dualidade, no âmbito da representação discursiva os valores muitas vezes limitavam-se a dicotomia entre a mulher honesta, que é boa mãe e cuja atuação tem por fim o amor e a educação de seus familiares, e a rameira, mulher que já foi honrada e que perdeu a pureza pelas agruras da vida e cuja simples presença circunstancialmente implicava na desvirtuação de outras mulheres e na subversão dos valores familiares. ${ }^{16}$

Como o conto $A$ cigarreira evidencia, os ganhadores, caixeiros, gaiatos e demais homens que viam as operárias indo ao trabalho logo cedo pelas ruas do Recife sentiam-se à vontade para assediá-las. Uma vulnerabilidade construída socialmente por valores coletivos atribuídos às operárias, em certa medida, pela própria pauperização das mulheres que trabalhavam nas fábricas. Como a fala do inspetor de higiene deixa subentendido, havia um limiar passível de ser atravessado por trabalhadoras industriais

\footnotetext{
${ }^{16}$ Ao analisar os discursos de economia política na França do século XIX, Joan Scott, já percebia que as mulheres trabalhadoras eram recorrentemente figuradas como prostitutas em potencial. Ou seja, a análise do uso de categorias relacionadas à prostituição para o período deve ser operada com a consciência de que o termo tinha conotações sociais muito mais amplas do que o circuito de trabalho relacionado ao meretrício. O termo era uma condição de ameaça a valores relacionados a família e a ordem social (Scott, 1988:143).
} 
pobres para o mundo da prostituição, mesmo que em condições transitórias de desemprego. $\mathrm{O}$ meretrício era uma realidade que pode ter sido vivenciada por algumas das cigarreiras e que fazia parte do convívio de outras. ${ }^{17}$

Em 1903, época em que as folhas diárias ainda noticiavam os casos de suicídio da cidade, foi publicado o caso de Amélia Maria de Jesus que se prostituía havia um ano, condição que segundo um jornal the levou ao "desejo de libertar-se da existência". Jovem e pobre Amélia vivia em uma casa com tantas outras mulheres como ela, mas que se diferenciavam pelo ofício que desempenhavam - as outras "companheiras" eram "operárias da fábrica de tecidos" da Torre (A Província, 23 jul. 1903).

A convivência coletiva de mulheres pobres, entre operárias e prostitutas, sob um mesmo teto pode ser um indício de uma busca de autonomia que se distanciasse da exploração masculina, que corriqueiramente ocorria em forma de abuso sexual dentro da própria casa por parte de familiares (Graham, 1992). Outros costumes comuns das trabalhadoras podem ser também compreendidos como estratégias de proteção. Por exemplo, um dos traços mais documentados sobre as cigarreiras é o de que caminhavam coletivamente nas idas e vindas do trabalho, geralmente cantando e fazendo muito alarido, prática que poderia representar um mecanismo de segurança em reação à situação de insegurança em relação à integridade de seus próprios corpos face às investidas masculinas. Essas abordagens que eram vistas com descontração pelo narrador do conto $A$ cigarreira, por vezes chegavam às páginas da imprensa como expressões de uma renitente opressão que parecia irremediável por parte de homens, como era o caso de um ordenança da polícia que não teve o nome revelado e que, segundo certa publicação solicitada, "provoca constantemente as operárias com palavras obscenas, por

\footnotetext{
${ }^{17}$ Sobre o papel da prostituição na vida das habitantes de um centro urbano brasileiro do começo do século XX, recomendo a leitura do livro de Schettini (2006).
} 
não quererem elas aceitar seus gracejos" (Publicações..., 19 mai. 1905). ${ }^{18}$

No caso acima, elas pediam providências à própria polícia pela imprensa, como pedia providências o gerente da seção feminina da fábrica de cigarros contra "uns vadios que reúnem-se no beco junto ao mesmo prédio e incomodam muito as operárias, subindo as janelas e atirando pedras para o interior". Dois anos mais tarde ainda se repetiam pedidos de providências contra os que atiravam pedras na mesma seção onde trabalhavam as cigarreiras no centro do Recife (A Província, 27 ago. 1903; $A$ Província, 10 jan. 1905).

Naquele momento ser operária implicava em ser identificada com uma categoria social relacionada a uma condição de vulnerabilidade diretamente implicada por relações de gênero, Essa condição se evidenciava também na dificuldade que as operárias tinham em se manifestar ou se fazer ouvir pelos homens, seja pela "linguagem incorreta" que era risível aos caixeiros gaiatos, ou nas páginas da imprensa, em que eram basicamente personagens em matérias escritas por homens. Havia um terreno estéril para tentativas de construção de uma autorrepresentação pública por parte das cigarreiras, o que influía objetivamente em torno das concepções que envolviam a honra de cada uma delas e mesmo da categoria de trabalho enquanto coletividade a que pertenciam. $\mathrm{O}$ discurso que as situava como mulheres degeneradas pelo meio, além de naturalizar uma posição social que as expunha às agressivas invectivas masculinas, também colocava em risco o direito delas ao trabalho, como na apropriação do argumento moral que era eventualmente manifestado por grupos de operários cigarreiros. ${ }^{19}$

\footnotetext{
${ }^{18}$ Publicações do tipo não eram de autoria do corpo redacional dos jornais, geralmente o espaço era reservado a queixas de leitores/leitoras sobre os problemas cotidianos da cidade.

${ }^{19}$ A forma como os discursos circunscrevem as experiências e de uma maneira complementar essas experiências fundamentam as identidades coletivas é matéria de reflexão de Canning (1994).
} 
Talvez essa senda seja uma chave fundamental para compreender a entrada dessas mulheres no movimento operário. Ainda que seja uma tarefa melindrosa a de atribuir significados ou intenções à entrada dessas mulheres no movimento operário pelo simples fato de não existirem registros de seus discursos na documentação disponível para os dias atuais, há de se convir que todo ato de fala é um ato de identidade e o movimento operário propiciava um canal de protagonismo para que essas mulheres se manifestassem em eventos públicos e em lugares tidos como respeitáveis para a sociedade da época. De modo que o lugar simbólico que ocupavam nas solenidades e a forma sempre respeitosa com que os membros do Centro Operário se dirigiam a elas, geralmente como "senhoras honestas", talvez fosse uma das questões centrais para que determinadas trabalhadoras buscassem naquele espaço um lugar de construção de identidades sociais que estava para além de questões de classe. ${ }^{20}$

Esse tipo de vivência se adensou em pouco tempo. Em 1905 a classe dos cigarreiros entrou em greve novamente por causa de uma redução nos salários. Nessa greve, as mulheres tomaram papel ativo, até porque eram maioria da força de trabalho nas fábricas de fumo. Ou seja, a atuação das mulheres fortaleceu o movimento operário naquele momento, e em uma relação simbiótica, o movimento operário proporcionou as condições históricas para que elas conseguissem uma plataforma material $e$ discursiva para agenciar papéis sociais mais amplos. Se antes o ingresso delas nas fábricas de cigarro obedecia a duas razões principais, notadamente os salários mais baixos e a falta de organização política, a partir de então um desses eixos passa a ser descontruído. Além do que, era a partir da ocupação desse novo espaço social que as discussões em torno da equidade salarial

\footnotetext{
${ }^{20}$ A historiadora Joan Bak afirma que no Rio Grande do Sul os socialistas do movimento operário já se preocupavam com a questão feminina pelo menos desde idos de 1901, a autora salienta a maneira cortes no tratamento em relação às operárias como "uma estratégia consciente para ganhar o apoio das mulheres" Bak (2003:213).
} 
começaram a acontecer, ainda que por décadas essa reivindicação tenha permanecido como um ensejo frustrado.

Não é tarefa simples pontuar ou evidenciar o impacto dessas novas representações nas vidas das operárias cigarreiras. Não acredito que seja o tipo de caso que revolucionou uma consciência de gênero entre os sujeitos históricos da época. No entanto, a nível local houve uma expansão na forma de percepção daquele determinado grupo de mulheres. Pequenos indícios em cantos de jornais podem ser reveladores disso, como uma notinha publicada em um jornal recifense que noticiava a mudança de nome de uma troça carnavalesca, em 1904, que chamava-se Bloco das Cigarreiras e passou a se chamar Bloco das Cigarreiras Revoltosas, dando a ver o ritmo lento e gradual da marcha da mudança histórica desabrochando em paisagens inusitadas, como na expressão de brincantes do carnaval em Recife (Carnaval..., 16 fev. 1904). ${ }^{21}$

\section{Considerações finais}

O estudo de caso das cigarreiras teve por objetivo implícito a tentativa de situar historicamente a circulação e o impacto de práticas discursivas circunscritas no contexto da divisão sexual do trabalho no Brasil no início do século XX. Para tanto, as narrativas arroladas até aqui buscaram, por um lado, identificar quais os interesses de determinados agentes sociais em lançar mão da retórica que ambicionava interditar o acesso ao trabalho feminino nas fábricas de cigarro do Recife. E por outo, analisar algumas das estratégias protagonizadas pelas operárias para reagir a situações

\footnotetext{
${ }^{21}$ Desde pelo menos o carnaval de 1904 as cigarreiras desfilavam nas ruas exibindo uma identidade relacionada as suas lutas. Naquele ano estavam em um carro "com uma grande lagosta, búzio e caranguejo" ao lado do "d. Carnaval, o príncipe Confetti e as princesas Bisnaga e Serpentina", representando "a greve das cigarreiras da Lafayette, conduzindo as operárias apetrechos da sua profissão". Sobre a importância que os blocos de rua do carnaval recifense tinham à época para a afirmação das lutas e das identidades de classe, a pesquisadora Rita de Cássia Barbosa de Araújo escreveu contundentes linhas no artigo: Araújo (1997).
} 
de exploração moral e material que derivavam do contexto de ruptura dos papéis socialmente atribuídos a elas.

No específico caso da substituição da mão de obra masculina pela feminina nas fábricas de cigarro, pode-se perceber pelo menos três posições diferentes de setores sociais ocupados por homens que estavam diretamente envolvidos nos conflitos deflagrados pelo momento de transição. Grupos de cigarreiros que estavam no foco da questão ocupando o incômodo papel de força de trabalho a ser dispensada eram os mais altivos no posicionamento contrário ao trabalho feminino. Se, por um lado, esses trabalhadores tinham interesses econômicos objetivamente atrelados a sua posição, por outro, apoiavam-se em argumentações amplamente aceitas socialmente que relacionavam o trabalho industrial a representações que maculavam a moral das mulheres. Situação que transcende a competência de uma análise estritamente executada pelas "lentes mercantis" e que tem por base uma forte dimensão cultural.

A segunda posição é a do proprietário da fábrica Lafayette, cujas posições em torno do tema foram eventualmente compartilhadas por empresários de outras fábricas de cigarro do Recife. Manoel Pontes era um dos operadores da lógica que assimilava o trabalho feminino nas fábricas dentro de circunstâncias que acentuavam submissão e precariedade em relação aos homens. A mão de obra que do ponto de vista econômico lhe era conveniente para sanar o balanço financeiro da empresa, era contratada em conformidade com um rígido grau de hierarquização e controle. A forma como reagiu ao ser questionado sobre a demissão das cigarreiras que tinham integrado o movimento operário, insultando-as e violentando uma delas é um indício de como a produção econômica era beneficiária das representações sociais que entendiam a mulher operária como uma mulher de segunda categoria, para organizar $e$ disciplinar o trabalho dentro de suas fábricas. O caso em tela expõe como esse tipo de prática era estabelecido e amparado por um arquipélago de lugares sociais como a imprensa $e$ as forças de segurança pública. Tanto pelo fato de Manoel Pontes ter usufruído 
da possibilidade de explicar sua versão em um longo artigo nas primeiras páginas dos jornais de Recife - enquanto as cigarreiras que sofreram ofensas físicas não terem tido direito à palavra pública, quanto porque o proprietário não teve que prestar esclarecimentos à polícia pela violência cometida. Na verdade, a polícia foi guardar o prédio da fábrica em vigília contra possíveis retaliações por parte das operárias.

Por último, a postura dos membros do Centro Operário encontra divergências objetivas em relação ao posicionamento de segmentos dos homens cigarreiros que protestavam contra o trabalho das mulheres, o que evidencia a complexidade em harmonizar os interesses múltiplos do movimento em relação aos interesses dos trabalhadores. A documentação não traz à tona se essas divergências correspondem a circunstanciais desacordos entre grupos dentro do movimento. Mas, sim, que desde o princípio, as notas da direção publicadas na imprensa operária denotam a construção de uma retórica que buscava equalizar as divergências a partir da ideia de que os interesses de classe estavam acima das diferenças de sexo.

\section{Referências bibliográficas}

ARAÚJO, Rita de Cássia Barbosa de. "Carnaval do Recife: a alegria guerreira”. Estudos Avançados, São Paulo, vol. 11, n 29, 1997.

BAK, Joan. Classe, etnicidade e gênero no Brasil: a negociação de identidade dos trabalhadores na greve de 1906, em Porto Alegre. MÉTIS: História \& Cultura, vol.2, n 4, jul. / dez. 2003, pp.181-224.

CANNING, Kathleen. "Feminist History after the Linguistic Turn: Historicizing Discourse and Experience". Journal of Women in Culture and Society, vol. 19, n 2, Winter, 1994, pp.368-404.

Gallego, Francesc A. Martínez. The tocata and fugue of the urban factory. Working-class conflicts and work discipline in Valencia, 18401880. In: PiQUeRAS, José; ROZALÉn, Vincent (ed.). A social history of Spanish labour. Oxford, Berghanhn, 2007, pp.92-105. 
cadernos pagu (55), 2019:e195513 As cigarreiras revoltosas e o movimento operário: história da primeira greve feminina do Recife e as representações das mulheres operárias na imprensa

GRAHAM. Sandra Lauderdale. Proteção e obediência: criadas e seus patróes no Rio de Janeiro, 1860-1910. São Paulo, Companhia das Letras, 1992.

KeRGOAT, Danièle. Divisão sexual do trabalho e relaçóes sociais de sexo. Traduzido por Miriam Nobre [http://poligen.polignu.org/sites/poligen.polignu.org/files/adivisaosexua ldotrabalho_0.pd - acesso em: abril de 2015].

MACIEL, Osvaldo. Filhos do trabalho, apóstolos do socialismo os tipógrafos e a construção de uma identidade de classe em Maceió. Dissertação de mestrado, Departamento de História UFPE, 2004.

NASCIMENTO, Alcileide; LUZ, Noêmia. Liberdade, transgressão e trabalho. O cotidiano das mulheres na cidade do Recife (1870-1914). Caderno Espaço Feminino, vol. 25, n 1, jan-jun 2012.

NASCIMENTO, Luiz do. História da Imprensa de Pernambuco (18211954). Recife, EDUFPE, vol. VI, 1972

RAGo, Margareth. Do cabaré ao lar: A utopia da cidade disciplinar. Rio de Janeiro, Paz e Terra, $3^{\circ}$ ed., 1997.

RUIz, Vicki L.; KorROL, Virginia Sánchez. (eds.). Latinas in the United States: a historical encyclopedia.Virginia, Indiana University Press, 2006.

SCHETTINI, Cristiana. "Que tenhas teu corpo": uma história social da prostituição no Rio de Janeiro das primeiras décadas republicanas. Rio de Janeiro, Arquivo Nacional, 2006.

SCOTT, Joan. Gender: a useful category of historical analyses. Gender and the politics of history. New York, Columbia University Press. 1989.

. Gender and politics of History. New York, Columbia University Press, 1988.

SILVA, Elizabete Rodrigues da Silva. Fazer charutos: uma atividade feminina. Salvador, Dissertação (Mestrado em História), UFBA, Salvador, 2011.

SILVA, Marinete dos Santos. Clientes e circuitos da prostituição no Rio de Janeiro do século XIX. Dimensóes, vol.29, 2012, pp.374-391. 
SILVA, Esequiel Gomes da. "Momentâneas" e "Horizontais": as prostitutas nas crônicas de Artur Azevedo. Recorte, vol.11, $n^{\circ} 1$, janjun 2014, pp.1-12.

SoUZA, Felipe Azevedo e. A participação política das classes populares em três movimentos, Recife (c. 1880 - c. 1900). Tese (Doutorado em História), IFCH/UNICAMP, Campinas, 2018.

WeINSTEIN, Barbara. As mulheres trabalhadoras em São Paulo: de operárias não-qualificadas a esposas profissionais. cadernos pagu (4), Campinas-SP, Núcleo de Estudos de Gênero-Pagu/Unicamp, 1995, pp.143-171.

\section{Fontes primárias}

Jornal do Recife

Agradecimento. Jornal do Recife (PE), 13 de fevereiro de 1895.

Manifestação. Jornal do Recife (PE), 8 de outubro de 1895.

Operários cigarreiros. Jornal do Recife (PE), 3 de janeiro de 1899.

A Cigarreira. Jornal do Recife (PE), 29 de abril de 1900.

Fábrica Lafayette. Jornal do Recife (PE), 24 de janeiro de 1901.

Levante. Jornal do Recife (PE), 3 de setembro de 1903.

$1^{\circ}$ de Maio. Jornal do Recife (PE), 3 de maio de 1904.

Centro Operário. Jornal do Recife (PE), 5 de junho de 1904.

A festa do Gabinete. Jornal do Recife (PE), 27 de agosto de 1904.

Jornal do Recife (PE), 17 de maio 1905.

Protesto dos operários da Fábrica Lafayette. Jornal do Recife (PE), 11 de março de 1906.

\section{A Província}

A Província (PE), 25 de agosto de 1901.

Secção Variedades. A Província (PE), 11 de maio de 1901.

A Província (PE), 15 de janeiro de 1902. 
cadernos pagu (55), 2019:e195513 As cigarreiras revoltosas e o movimento operário: história da primeira greve feminina do Recife e as representações das mulheres operárias na imprensa

Agradecimento. A Província (PE), 19 de outubro de 1902 e 21 de outubro de 1902.

A Província (PE), 23 de julho de 1903.

A Província (PE), 27 de agosto de 1903.

Greve das Cigarreiras. A Província (PE), 3 de setembro de 1903.

O que diz o Centro Operário. A Província (PE), 3 de setembro de 1903.

Greve das Cigarreiras. A Província (PE), 5 de setembro de 1903.

Greve das Cigarreiras. A Província (PE), 6 de setembro de 1903.

Greve das Cigarreiras. A Província (PE), 10 de setembro de 1903.

Carnaval. A Província, 16 de fevereiro de 1904.

Serviço de Higiene. A Província (PE), 10 de maio de 1904.

Agradecimento. A província (PE), 18 de maio de 1904.

A Província (PE), 10 de janeiro de 1905.

Publicações solicitadas. A Província (PE), 19 de maio de 1905.

Monte Pio Popular. A Província (PE), 15 de novembro de 1905.

\section{Diário de Pernambuco}

Cigarreiras em greve. Diário de Pernambuco (PE), 3 de setembro de 1903.

Cigarreiras em greve. Diário de Pernambuco (PE), 5 de setembro de 1903.

Echo do Povo

A fome avassala. Echo do Povo (PE), 10 de dezembro de 1910. 